\title{
Locus heterogeneity in progressive familial intrahepatic cholestasis
}

\author{
Sandra S Strautnieks, Amir F Kagalwalla, M Stuart Tanner, R Mark Gardiner, \\ Richard J Thompson
}

\begin{abstract}
Progressive familial intrahepatic cholestasis (PFIC or Byler disease) is a rare autosomal recessive form of severe and fatal cholestatic liver disease. A locus for PFIC has recently been mapped to chromosome 18q21-q22 in the original Byler pedigree. This region harbours the locus for a related phenotype, benign recurrent intrahepatic cholestasis (BRIC), suggesting that these traits are allelic. Linkage analysis was undertaken in five consanguineous PFIC pedigrees from Saudi Arabia using marker loci (D18S69, D18S41， D18S64， D18S38， D18S42, D18S55, D18S68, and D18S61) which span the Byler disease/BRIC region on 18q21q22. In this family set the disease locus was excluded from this region, showing that locus heterogeneity exists for the PFIC phenotype.

( $f$ Med Genet 1996;33:833-836)
\end{abstract}

Key words: liver; cholestasis; familial; heterogeneity.

There are a number of separate identifiable cholestatic diseases with onset in childhood, some of which have obvious mendelian inheritance. Some are clearly syndromic, with non-hepatic manifestations, such as Alagille and Aagenaes syndromes. Others have characteristic histological or biochemical features. Progressive familial intrahepatic cholestasis (PFIC or Byler disease, OMIM 211600) is an example of the latter. PFIC was first described in a large Amish pedigree ${ }^{1}$ and patients with the same disease phenotype have now been described in many populations. ${ }^{2}$ Inheritance is autosomal recessive with a high incidence of parental consanguinity. Despite the fact that the term PFIC has been applied to a variety of familial cholestatic phenotypes, ${ }^{3}$ the patients used in this research and the discussion thereof are restricted to the phenotype corresponding to that seen in the original Byler family.

The disease presents in the first few months of life with intense pruritis, jaundice, malabsorption, loose stools, and failure to thrive. A number of characteristic features distinguish PFIC from other cholestatic diseases. Initially there appears to be a relapsing course, with clearing of jaundice between episodes, but progression occurs to severe persistent cholestasis and biliary cirrhosis. The episodic jaundice is associated with a marked rise of serum bile acids and depression of biliary bile acids ${ }^{4}$ and these changes become persistent. The most unusual and striking feature of these children is that neither the serum cholesterol nor the $\gamma$-glutamyl transpeptidase $(\gamma \mathrm{GT})$ are raised. ${ }^{5}$ These findings in particular differentiate PFIC from other cholestatic diseases, as bile is the only route of cholesterol excretion, and $\gamma \mathrm{GT}$ is released from the biliary epithelium by any damage, particularly by bile acids. Liver biopsy shows marked intrahepatic cholestasis with progressive fibrosis. Death usually occurs in the first or early in the second decade of life.

Benign recurrent intrahepatic cholestasis (BRIC, OMIM 243300) is a similar but phenotypically quite distinct condition. BRIC patients also have intermittent cholestasis and jaundice but remain otherwise well and there is no progression to chronic liver disease. A BRIC locus has been mapped to chromosome $18 \mathrm{q} 21-22$ in an isolated Dutch population with a presumed founder mutation. ${ }^{6}$ Subsequently, in members of the original Byler family, a locus for PFIC has been mapped to the same chromosomal region. ${ }^{7}$ It is assumed that the causative gene will be involved in bile acid transport within the liver, but no plausible candidate genes have yet been identified in this region of chromosome 18 .

Linkage analysis was undertaken in five unrelated consanguineous Saudi Arabian families segregating PFIC, using marker loci spanning the region of chromosome 18 to which BRIC and PFIC have been mapped. No regions of homozygosity were seen in any of the affected people, and negative lod scores across the region were obtained in all families. This provides unequivocal evidence for locus heterogeneity in PFIC.

\section{Materials and methods}

SUBJECTS

Six affected children from five first cousin marriages, their parents, and a total of 12 unaffected sibs were analysed (fig 1). Six further children from family 4 are known to have already died from severe cholestatic liver disease. The five families are not known to be related. The affected subjects all have jaundice with onset in the first three months of life, pruritis with maximum age of onset of 7 months, and severe failure to thrive. All the affected children have biochemical and histological evidence of marked cholestasis, with very raised serum bile acid concentrations, low or normal cholesterol levels, and normal $\gamma$ GT levels (table 1). They all have liver biopsy appearances of severe intrahepatic cholestasis and cirrhosis. 
Table 1 Clinical data of the patients in this study. These are the most recent available for each patient. The normal ranges of the laboratory in which the estimations were made are given

\begin{tabular}{|c|c|c|c|c|c|c|c|c|c|}
\hline Family & Patient & $\begin{array}{l}\text { Age at } \\
\text { presentation } \\
\text { (y) }\end{array}$ & $\begin{array}{l}\text { Current } \\
\text { age } \\
(y)\end{array}$ & $\begin{array}{l}\text { Bilirubin } \\
\text { (NR 0-22 } \mathrm{mol} / \mathrm{l})\end{array}$ & $\begin{array}{l}\text { Aspartate } \\
\text { transaminase } \\
\text { (NR 11-55 IU/l) }\end{array}$ & $\begin{array}{l}\gamma \text {-Glutamyl } \\
\text { transpeptidase } \\
(N R \text { 5-37 IU/l) }\end{array}$ & $\begin{array}{l}\text { Alkaline } \\
\text { phosphatase } \\
\text { (NR 100-280 IU/l) }\end{array}$ & $\begin{array}{l}\text { Cholesterol } \\
\text { (NR 2.3-6.9 mmolll) }\end{array}$ & $\begin{array}{l}\text { Bile acids } \\
\text { (NR 0-8.9 } \mu \mathrm{mol} / \mathrm{l})\end{array}$ \\
\hline 1 & II. 2 & 0.2 & 5 & 171 & 291 & 36 & 760 & 1.3 & 256 \\
\hline 2 & II. 3 & 0.25 & 2 & 335 & 259 & 16 & 794 & 3.77 & 131 \\
\hline 3 & II. 1 & 0.1 & 11 & 20 & 151 & 19 & 1877 & 5.48 & 291 \\
\hline 4 & II. 7 & 0.5 & 1.5 & 247 & 1352 & 43 & 746 & 4.9 & 123 \\
\hline 5 & II. 2 & 0.75 & 9 & 101 & 119 & 28 & 471 & 5.5 & 237 \\
\hline 5 & II. 3 & 0.7 & 6 & 95 & 131 & 21 & 996 & 3.8 & 462 \\
\hline
\end{tabular}

$\mathrm{NR}=$ normal range.

Family 1

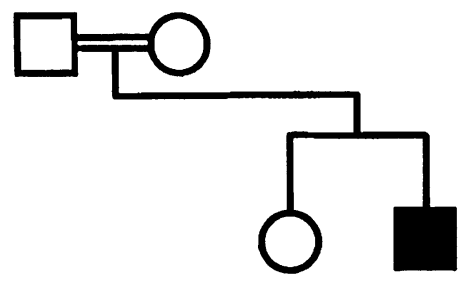

D18S69

D18S41

D18S64

D18S38

D18S42

D18S55

D18S68

D18S61

\begin{tabular}{|c|c|c|c|}
\hline$\ldots$ & -.. & 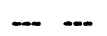 & -- -- \\
\hline 5209 & 197197 & 209197 & - \\
\hline 4324 & 328336 & 324336 & 324328 \\
\hline 166166 & 162166 & 166166 & 166162 \\
\hline 186190 & 190186 & 190190 & 186190 \\
\hline 144144 & 144144 & 144144 & 14414 \\
\hline 284274 & 276274 & 284274 & 284276 \\
\hline 232226 & 230212 & 232212 & 23223 \\
\hline
\end{tabular}

Family 3

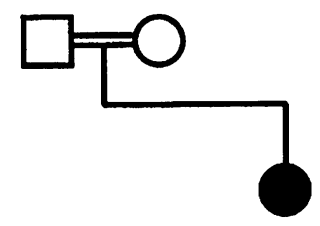

D18S69

D18S41

D18S64

D18S38

D18S42

D18S55

D18S68

D18S61

\section{$\begin{array}{lll}194194 & 194194 \quad 194194\end{array}$}

$\begin{array}{lll}328342 & 326328 & 328326\end{array}$

$\begin{array}{lll}166166 & 164166 \quad 166164\end{array}$

$\begin{array}{lll}196186 & 194190 \quad 196194\end{array}$

$\begin{array}{lllll}138146 & -\cdots & \cdots & 138144\end{array}$

$274274 \quad 284282 \quad 274284$

$226230 \quad 222212 \quad 226222$
$205205 \quad 201205 \quad 205201$
D18S69

D18S41

D18S64

D18S38

D18S42

D18S55

D18S68

D18S61
Family 2

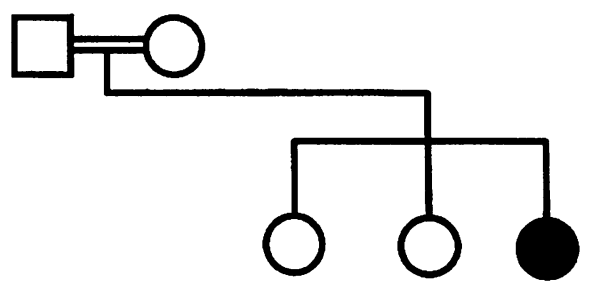

D18S69

D18S41

D18S64

D18S38

D18S42

D18S55

D18S68

D18S61
D18569

D18S41

D18S64

D18S38

D18S42

D18S55

D18S68

Family 5
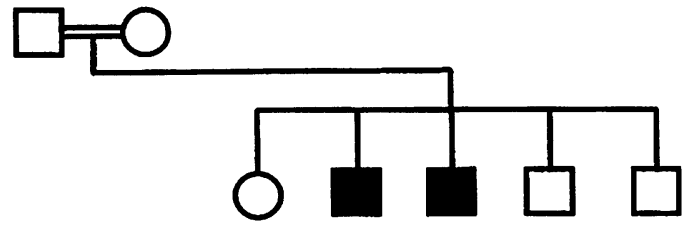

$$
\begin{aligned}
& \begin{array}{llllllll}
194194 & 206198 & 194198 & 194206 & 194198 & 194198 & 194198
\end{array} \\
& \begin{array}{llllllll}
205205 & 207203 & 205203 & 205207 & 205203 & 205203 & 205203
\end{array} \\
& \begin{array}{llllllll}
324324 & 324336 & 324324 & 324324 & 324324 & 324324 & 324324
\end{array} \\
& \begin{array}{llllllll}
166166 & 166166 & 166166 & 166166 & 166166 & 166166 & 166166
\end{array} \\
& \begin{array}{lllllllll}
190190 & 186190 & 190186 & 190186 & 190186 & 190186 & 190186
\end{array}
\end{aligned}
$$

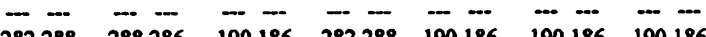

$$
\begin{aligned}
& \begin{array}{lllllll}
282288 & 288286 & 190186 & 282288 & 190186 & 190186 & 190186 \\
214224 & 214226 & 224214 & 214214 & 224226 & 224214 & 214214
\end{array}
\end{aligned}
$$

Figure 1 Pedigrees of the PFIC families used in this study. All marriages are between first cousins. Sibs unavailable for genotyping are not shown. The allele data at the marker loci used is shown beneath each subject. The numbers are allele sizes and are based on $P C R$ product sizes measured in mobility units. Genotypes unavailable are given as (-----). 


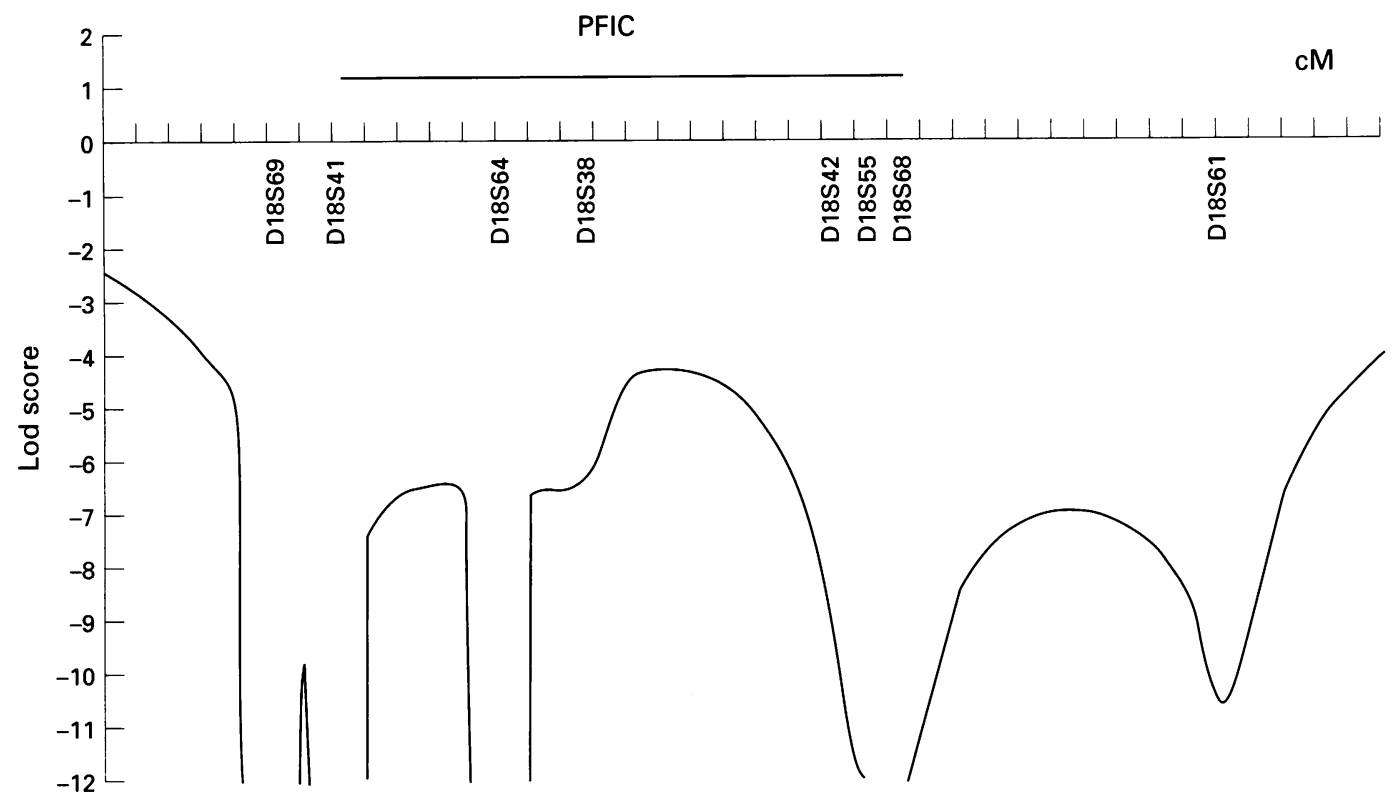

Figure 2 Multipoint analysis of PFIC region of chromosome 18q21-22. Horizontal scale marked in 1 cM intervals. Vertical scale shows location lod score. The PFIC locus previously described is shown above the axis, as defined by limiting recombinants. ${ }^{7}$ The sex averaged distances in cM between loci are D18S69-2-D18S41-5-D18S64-3-D18S387.5-D18S42-1-D18S55-1-D18S68-9-D18S61.

MARKER TYPING

Genomic DNA was extracted from white cells by standard methods. DNA was amplified by the polymerase chain reaction (PCR) using fluorescently labelled primers. The markers used were D18S69, D18S41, D18S64, D18S38, D18S42, D18S55, D18S68, and D18S61. Primer sequence and allele frequency data for these markers are available from the Genome Database (GDB). PCR was performed in 96 well microtitre plates (Hybaid). Each well contained $20-50 \mathrm{ng}$ of genomic DNA; $1.5 \mathrm{mmol} / 1 \mathrm{MgCl}_{2} ; 1 \times$ reaction buffer (Advanced Biotechnologies, UK); $200 \mathrm{mmol} / \mathrm{l}$ each of dGTP, dATP, dTTP, and dCTP; $50 \mathrm{ng}$ of each primer; and $0.2 \mathrm{U}$ of Red Hot DNA polymerase (Advanced Biotechnologies, UK), in a total volume of $15 \mu \mathrm{l}$. Thirty cycles were performed in a thermocycler (Hybaid Omnigene $\left.{ }^{\mathrm{TM}}\right)$. Alleles were separated through a $6 \%$ polyacrylamide electrophoresis gel for three to four hours at a rate limiting voltage of 1000 volts using a model 373A DNA sequencer (Applied Biosystems). Analysis of the allele sizes was carried out by GENESCAN ${ }^{\mathrm{TM}} 672$ (version 1.2) and Genotyper softwares (Applied Biosystems) using GENESCAN ${ }^{\mathrm{TM}}$-500 TAMRA.

\section{LINKAGE ANALYSIS}

Linkage analysis was carried out assuming fully penetrant autosomal recessive inheritance with a disease allele frequency of 0.001 . Multipoint analysis was performed using the MAPMAKER/HOMOZ program. ${ }^{8}$ This allows very rapid calculation of multipoint lod scores in small inbred families. Allele frequencies were obtained from GDB with frequencies restricted to not less than 0.10 .

\section{Results}

No significant common regions of homozygosity were identified (fig 1). At all the marker loci examined, with the exception of D18S42, at least one person was homozygous. In seven of the 11 such loci the parents were also homozygous, rendering the corresponding meioses uninformative. Both children in family 5 were homozygous at D18S64 as was one parent. In family 5, the homozygosity seen at D18S68 and D18S61 is not common to both patients indicating obligate recombinants.

The statistical significance of these results can be represented as a multipoint lod score. The individual family multipoint lod scores were consistently negative over the whole region examined, though as each family is small no one family achieved a region of exclusion (defined as a lod score of less than -2) of more than a few centimorgans. However, the maximum total lod score assuming locus homogeneity was -4.3 over the genetic interval defined by D18S69 and D18S61 (fig 2). The unlikely possibility that each family has acquired a second disease allele by marriage can be allowed for by increasing the disease allele frequency to 0.10 . Under this model the maximum lod score over this region is -2.9 .

\section{Discussion}

The absence of homozygosity in a set of closely linked markers has entirely excluded the PFIC/ BRIC locus on chromosome 18 in these families, assuming inheritance of two copies of a disease gene from a great grandparent. The only other mechanism which needs to be considered is that all the families have acquired a disease allele by marriage to an unrelated person. Even this possibility can be excluded by 
the observation of obligate recombinants within the region.

The patients used in this study are phenotypically indistinguishable from the affected subjects in the Byler family. Although the mapping of the PFIC locus involved only two affected subjects, a large number of ancestral meioses were examined in the analysis. ${ }^{7}$ Therefore the likelihood of the observed common segments being inherited by chance, and therefore not containing the disease gene, was 1 in $1 \times 10^{5}$. We have excluded this region of $18 \mathrm{q}$ in our families. These new data therefore show locus heterogeneity.

The biochemical features of PFIC suggest a defect in the transport of bile acids from blood to bile. Bile acids are synthesised by hepatocytes and are actively excreted in bile. Ninety percent of the bile acid content of bile is reabsorbed in the small intestine and enters the portal circulation. In normal people uptake of bile acids by hepatocytes achieves a first pass clearance of $80-90 \%$. Under normal circumstances they are therefore subject to an efficient enterohepatic circulation. As a result total serum bile acids are normally maintained at less than $10 \mu \mathrm{mol} / 1$ in peripheral blood. To achieve this there are highly efficient bile acid uptake mechanisms on the basolateral surface of hepatocytes. $^{9}$ It is assumed that cytoskeletal elements are involved in transcytotic movement of bile acids, ${ }^{10}$ and that there are multiple, quite distinct, transporters on the canulicular surface. ${ }^{11}$ There are a number of anatomical sites at which bile acid transport could fail: basolateral membrane, intracellular transporters, or at the canulicular membrane. The severity of the liver disease in PFIC suggests an intracellular accumulation of bile acids. In contrast, a failure of uptake at the basolateral membrane would be unlikely to lead to severe hepatitis and cirrhosis, making this an implausible site for the causative defects in PFIC. Therefore, the lumenal membrane or the cytoskeleton would seem to be the most likely candidates for the site of the defect. Electronmicroscopy of PFIC liver biopsies shows pericanulicular microfilamental condensation, as seen in phalloidin administration, suggesting that abnormalities of the cytoskeleton may underlie PFIC. ${ }^{12}$ However, similar changes have been noted in extrahepatic biliary obstruction. ${ }^{13}$ This may therefore be a secondary effect.

There is evidence in some BRIC families of a phenotype associated with the carrier state. Mothers of children with BRIC, themselves obligate heterozygotes, appear to have an increased incidence of cholestasis of pregnancy. ${ }^{14}$ This suggests that the defect in BRIC/PFIC is in a mechanism in which there is an excess functional capacity in normal people and in which heterozygotes have adequate capacity and therefore a normal phenotype until stressed. These new data indicate that there are at least two genes capable of causing phenotypically indistinguishable critical disruption of bile acid transport, probably at the same cellular site.
Cloning of the genes which cause PFIC will greatly increase our understanding of normal bile acid transport mechanisms in the liver. Furthermore, although it appears that the two distinct phenotypes of PFIC and BRIC are allelic, PFIC itself exhibits locus heterogeneity. This is not, of course, the first instance in which linkage studies have shown that apparently distinct phenotypes represent an allelic series or that an apparently homogeneous phenotype encompasses locus heterogeneity. Recent studies of the fibroblast growth factor receptor (FGFR) genes in the craniofacial dysmorphology syndromes Crouzon disease (arising from mutations in FGFR2 ${ }^{15}$ ) and Pfeiffer syndrome (an allelic variant at FGFR2, ${ }^{16}$ but also caused by mutations in FGFR $1^{18}$ ) are good examples Once again our understanding of genetics will require and allow us to redefine clinical syndromes.

We are very grateful for the cooperation of the patients and their families. RT is a Wellcome Trust Medical Graduate Research Training Fellow.

1 Clayton RJ, Iber FL, Ruebner BH, McKusick VA. Byler's disease: fatal familial intrahepatic cholestasis in an Amish kindred. F Pediatr 1965;67:1025-8.

2 Nielsen IM, Ornvold K, Jacobsen BB, Ranek L. Fatal familial cholestatic syndrome in Greenland Eskimo children. Acta Paediatr Scand 1986;75:1010-16.

3 Jacquemin E, Setchell KD, O'Connell NC, et al. A new cause of progressive intrahepatic cholestasis: 3 betahydroxy-C27-steroid dehydrogenase/isomerase deficiency. 7 Pediatr 1994;125:379-84

4 Whitington PF, Freese DK, Alonso EM, Schwarzenberg SJ, Sharp HL. Clinical and biochemical findings in progressive familial intrahepatic cholestasis. $\mathcal{F}$ Pediatr Gastrenterol Nutr 1994;18:134-41.

5 Maggiore G, Bernard O, Riely C, et al. Normal $\gamma$-glutamyltranspeptidase activity identifies group of infants with poor prognosis. F Pediatr 1987;111:251-2.

6 Houwen RH, Baharloo S, Blankenship K, et al. Genome screening by searching for shared segments: mapping a gene for benign recurrent intrahepatic cholestasis. Nature Genet 1994;8:380-6.

7 Carlton VE, Knisely AS, Freimer NB. Mapping of a locus for progressive familial intrahepatic cholestasis (Byler disease) to 18q21-q22, the benign recurrent intrahepatic cholestasis region. Hum Mol Genet 1995;4:1049-53.

8 Kruglyak L, Daly MJ, Lander ES. Rapid multipoint linkage analysis of recessive traits in nuclear families, including homozygosity mapping. Am f Hum Genet 1995;56:519-27.

9 Hagenbuch B, Stieger B, Foguet M, Lubbert H, Meier PJ. Functional expression cloning and characterization of the hepatocyte $\mathrm{Na}+/$ bile acid cotransport system. Proc Nat Acad Sci USA 1991;88:10629-33.

10 Frimmer $M$, Ziegler $\mathrm{K}$. The transport of bile acids in liver cells. Biochim Biophys Acta 1988;947:75-99.

11 Inoue $M$, Kinne $R$, Tran T, Arias IM. Taurocholate transport by rat liver canalicular membrane vesicles. Evidence for the presence of an $\mathrm{Na}+$-independent transport system. f Clin Invest 1984;73:659-63.

12 Weber AM, Tuchweber B, Yousef I, et al. Severe familia cholestasis in North American Indian children: a clinical model of microfilament dysfunction? Gastronterology 1981;81:653-62.

13 Adler M, Chung KW, Schaffner F. Pericanalicular hepatocytic and bile ductular microfilaments in cholestasis in tocytic and bile ductular microfilam.
man. Am f Pathol 1980;98:603-16.

14 de Pagter AGF, van Berge Henegouwen GP, ten Bokkel Huinink JA, Brandt KH. Familial benign recurrent intrahepatic cholestasis. Interrelation with intrahepatic cholestasis of pregnancy and from oral contraceptives? Gastroenterology1976;71:202-7.

15 Reardon W, Winter RM, Rutland P, Pulleyn LJ, Jones BM, Malcolm S. Mutations in the fibroblast growth factor receptor 2 gene cause Crouzon syndrome. Nature Genet receptor 2 gene

16 Lajeunie $\mathrm{E}$, Wei $\mathrm{Ma} \mathrm{H}$, Bonaventure J, et al. FGFR2 mutations in Pfeiffer syndrome. Nature Genet 1995;9:108.

17 Rutland P, Pulleyn L, Reardon W, et al. Identical mutations in the FGFR2 gene cause both Pfeiffer and Crouzon syndrome phenotypes. Nature Genet 1995;9:173-6.

18 Muenke M, Schell U, Hehr A, et al. A common mutation in the fibroblast growth factor receptor 1 gene in Pfeiffe syndrome. Nature Genet 1994;8:269-74. 